\title{
"WRITING INTO THE RUPTURE": VISUAL SELVES IN MARY-KIM ARNOLD'S LITANY FOR THE LONG MOMENT
}

\section{HANA RIVERS}

"The materiality of history is [...] what will not be ordered, what does not coagulate and cohere...' history' becomes 'visible' not in its narrative representation, but in its defiance of the dominant regimes of representability."-Lisa Lowe, Immigrant Acts:

On Asian American Cultural Politics

"I am writing into the rupture, the absence left there."-Mary-Kim Arnold, Litany for the Long Moment

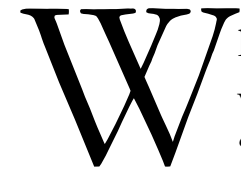
hat does it mean to "write into the rupture"? If absence refers to a lack, what does it mean when that lack inheres as a remainder, something "left there"? In Litany for the Long Moment, a text that is at once a lyric essay, a poem, a collage, and an assemblage of references, Mary-Kim Arnold does not attempt to answer these questions with any fixed certainty. Instead, she suspends them from the expectation that they will necessarily be answered. Arnold's text refuses easy answers regarding the themes it probes, including cultural dislocation, forgetting, alienation, and interior-versus-exterior modes of being. Born in Seoul, Korea and adopted to the U.S. as a child, Arnold's upbringing in New York among white family members and peers spurred her to explore a central question: what does it mean to be a self in relation to past and other selves?

This interrogation of relationality manifests in the text's form. By and large, Litany for the Long Moment defies adherence to literary genre. Though the text is studded with court documents, letters, photographs, and other memorabilia, these evidential objects do not hold the promise of closure or remembrance. Instead, their existence on the page, and Arnold's engagement with them throughout the text, opens up problems ("ruptures") that cast the notion of a stable self into question. By "writing into the rupture," Arnold does not promise readers any of the answers that she herself is searching for or provide access to whatever truth about the past that these memorabilia ostensibly promise (Arnold 96). Rather, she engages with them through analysis, recall, and conversation with photographers, poets, and Asian American writers, ambivalently thinking across the terrain of identity while refusing to adhere to representative tropes.

It is impossible to read this text without thinking through the role of photography, especially considering that the "long moment" referenced in its title is a direct allusion to long exposure photography. Throughout the text, Arnold continually interweaves reflections on and allusions to the work of literary theorist Roland Barthes and the photographer Francesca Woodman, an artist of the 1980s

Meliora Vol. 1, Issue 1 
known for her long exposure photographs and her use of her own body as a photographic subject. While some critics have deemed her photographs selfportraits, others have claimed that to impose this reading onto them negates Woodman's project as an artist, one which aims to posit the photographic subject as somehow inexpressible. Woodman figures herself as a continually evasive subject by obscuring her body through reflection, movement, and cropping, revealing the self as un-representable in modes (of which photography is one) that aim to capture a stable reality. Harriet Riches claims that “[Woodman's] camera worked to displace any 'essence' of identity" (Riches 99). Woodman's refusal to display any identificatory 'essence' mirrors Arnold's insistence on representing the folds and crevices of selfhood without adhering to pre-existing answers or tropes.

In order to provide context for the text before entering into a literary analysis, it is relevant to consider the nuances of visual memory through the lens of Barthes' work on photographic referents. That Arnold uses Woodman's work as a jumping-off point for her own is no surprise-Litany for the Long Moment evades genre as much as it denies a stable self throughout time. In particular, much of the text is centered on the divide between present and past self. The author tries and fails to grasp memories which may or may not have actual footing in reality: a dusty courtyard, a ripe persimmon. She reflects on a photograph of herself as a child as someone who appears familiar but with whom she feels no personal identification, a child who speaks a language she cannot, who houses memories she does not. If we see ourselves represented in a photograph that we do not remember having been taken, there is an inherent disjunction between our lack of memory about that moment in time and the physical evidence that the photograph offers. In relation to photographic subjects, Barthes states, 'I call 'photographic referent' not the optionally real thing to which an image or a sign refers but the necessarily real thing which has been placed before the lens, without which there would be no photograph" (Barthes 76). While photographic subjects are real in that without them there would be no existing photograph, the photograph itself is not necessarily representative of that subject-in other words, the signifier (the photograph) is not bound to the signified (the subject). Instead, the subject, hovering ghostlike behind its representative image, evades photographic capture as the 'real,' a dynamic epitomized in Francesca Woodman's work.

As in Arnold's dissociation with the photograph of her childhood self, memory does not represent experience. Just as photographs fail to truly represent the subjects they ostensibly capture, Arnold's memories of the past fail to represent what actually happened. In turn, as both memory and photography fail to pin down lived experience, time is made unstable and filled with gaps. These gaps make it difficult to reconcile who we have been with who we are, or who we will be. Arnold leans into these gaps throughout the text, citing artists and scholars such as Barthes and Woodman who posit the photograph as a site of loss, death, and subjective un-

Meliora Vol. 1, Issue 1 
representability to frame her personal parsing of her adoptive past. In doing so, she attempts to express a truth beyond simple disclosure, to "leave some record of a life that resists reduction, simplification, erasure" (Arnold 40).

Both photography and the larger discourse of Asian American race studies are productive fields for considering what it means to be an unmarked subject, in that each gives rise to questions about who or what is representable. In order to understand the nuance of Arnold's engagement with the representative failure of photography, it is first necessary to frame the text through the lens of Asian American literary studies. In particular, Arnold's work on photography is closely linked to the disjunction between racialized bodies and interior experience. It is important to note that the term 'Asian American' has been oft debated by scholars who call for alternate, more expansive language for this type of racial embodiment. For example, Asian American literature scholar Kandice Chuh underscores the "prediscursive meaninglessness of identificatory terms like 'Asian American' in terms of their lack of ethnic, historical, or individual particularity" (Chuh 86). Much of Chuh's scholarship centers around a rejection of identificatory meta-narratives. Out of this rejection, I raise the question: is Litany for the Long Moment a categorically 'Asian American' text? I hesitate to curb the nuance of Arnold's project by folding it neatly into an existing category of literature. In my project, however, I use the term 'Asian American' largely to evoke the seriously referential status of Arnold's work; Litany for the Long Moment is constantly in conversation with other Asian American writers, including Korean novelist Theresa Hak Kyung Cha and Korean poet Myung Mi Kim. Throughout the text, Arnold uses photographic ruptures to discuss racial discourses of alienation, a key parallel that is important to consider when thinking about the larger implications of visual representation in Asian American literary studies.

Discourses of integration and racial inclusion often champion visual representation as a mode by which to funnel certain unmarked subjects into dominant social circles. In recent years, such emphasis on visual representation has manifested in the rise of Asian American characters portrayed in films and other manifestations of popular culture. ${ }^{1}$ In relation to the problematization of the very term 'Asian American,' many race studies scholars who think within the interstices of identity argue that this inclusionist mode skims over the textured terrain of a multitude of identities, including ones that do not fit into dominant schemas. For example, subjects of mixed-race identity, those whose ethnic backgrounds stray from the dominant light-skinned, East Asian prototype, and transnational adoptees might not feel 'represented' by those from which they deviate (and, in turn, those who are

\footnotetext{
${ }^{1}$ Take the 2018 film Crazy Rich Asians, for instance, which was lauded by critics as highly inclusive for its allAsian casting, despite the fact that all of its actors were light-skinned East Asian individuals (although it takes place in Singapore, where there is a high population of Chinese Muslims), and the film's 'subversive' power dynamics still rested upon the main family's immense wealth.
} 
often at the helm of the representation politics that ostensibly facilitate 'inclusion'). Ultimately, a rejection of inclusionist modes of visual representation makes space for a nuanced, heterogeneous, and particular approach to thinking about identity.

Arnold is especially fascinated by Cha's genre-bending novel Dictee, an avant-garde multimedia work that, like Litany, includes photographs, letters, and other visual elements in addition to text. In an essay on Dictee, media studies scholar Thy Phu argues that visual texts often critique visuality in favor of a looser mode of autobiographical representation that departs from pre-existing molds of being. She states that "while the politics of visibility...are often embraced by critics as an effective means of redressing historical exclusions and erasures, it is unable to explain the persistence of various types of invisibility - 'unmarked' [subjects]" (Phu 17-18). Phu refers to subjects that have been historically erased or excluded as "unmarked" in that they remain invisible even in the realm of visibility politics. Throughout my project, however, I will use the term unmarked subjects paradoxically, to refer to individuals whose bodies are marked by race, but whose cultural or interior experience does not align with such a marking. Arnold is one such subject. Due to her upbringing in America, her Korean body is at odds with her lack of connection to Korean (or generally Asian) culture. Yet, as Phu argues, unmarked subjects such as Arnold find various other ways to depict themselves without falling into the invisibilizing violence of existing modes of representation. What does it mean to be an unmarked subject? Who, or what, is representable? Arnold's text, in its lucid exploration of memory, identity, language, the body, and cultural dislocation, certainly embraces these questions of representability.

Litany for the Long Moment is in conversation with both the race studies scholarship around bodily representation and the photographic theory around temporal instability. Against this backdrop, how and why does the photographic subject in Litany for the Long Moment rupture the stable self? Ultimately, as I argue, literature which engages the photographic reveals the failure of visual representation to integrate unmarked subjects into dominant categories of identity (Phu 19). While inclusion rhetoric configures visual representation as a way to include minority groups in spaces where they would otherwise be excluded, it fails to account for those subjects made invisible even by dominant groups within minority communities. In Litany for the Long Moment, Arnold's engagements with visuality rupture our notion of a stable self. This unsettling then opens up space for us to disidentify with the notion that racial bodies signify certain cultures or histories, and depart from the invisibilizing idea that visual representation is a sufficient mode of racial empowerment. Arnold ultimately reveals that representation cannot verify or authorize being, and throughout the text she figures lack as an opening through which she rearticulates what it means to be a self. 


\section{Past, Present, and the Photographic Self}

"Every photograph contains its future death and is therefore catastrophic."-Roland Barthes, Camera Lucida

Why is it that photographs are so often discussed in conjunction with the experience of loss? We turn to photographs in order to conjure memories of a deceased person, or to feel again the transient emotions that we experienced at some particular moment in our youth. Yet the moments captured via photography never perfectly align with what we conceive of as memory. Instead, photographs serve merely as representations of that which we can no longer access. Photography is a medium that claims to transform an unstable reality into a stable one; however, this stabilizing is an impossible task. While photographs certainly conjure memories within us, memory itself is un-representable through visual means. Moreover, even photographs themselves are material objects that bend, distort, and fade. Therefore, everlasting power is a falsehood when it comes to both physical and memorial stability. Despite our preconceived notions or the claims of the field of photography, the realities we believe to be stable always hold the possibility of dissolving, whether materially or mentally.

Throughout Litany, Arnold's use of memorabilia reveals the alienating disjunction between memory (or lack thereof) and visual remains. The memories that inhere as pictures in our mind's eye are very rarely reflected in what we see in a photograph. In the text, Arnold recalls the dispersed, drunken recollections of a group of fellow adoptees: "A bowl of persimmons. / Dogs barking in a fenced yard. / A man in a dark suit, standing at a gate" (Arnold 97). These images are both singular and fleeting, both specific enough that we could have experienced them and unspecific enough that we could have dreamed them. For Arnold, although memories take visual forms, they are unable to be 'confirmed' in the form of a concrete medium, notwithstanding their vividness in our mind. Relinquishing the unknowability of the past, Arnold states, "I will never know for certain what transpired in those first two years of my life" (Arnold 5). Here, Arnold's prose reveals the inherent instability of memory as it aligns with the so-called past. Out of the disjunction between concrete reality and the pictures of memory emerges photography's main thrust. Arnold's project reveals our expectation of the fixed image to offer us some sort of closure, consolation, or 'truth' beyond its role in representing a moment in time. This is an impossible and unfulfillable hope.

Meliora Vol. 1, Issue 1 


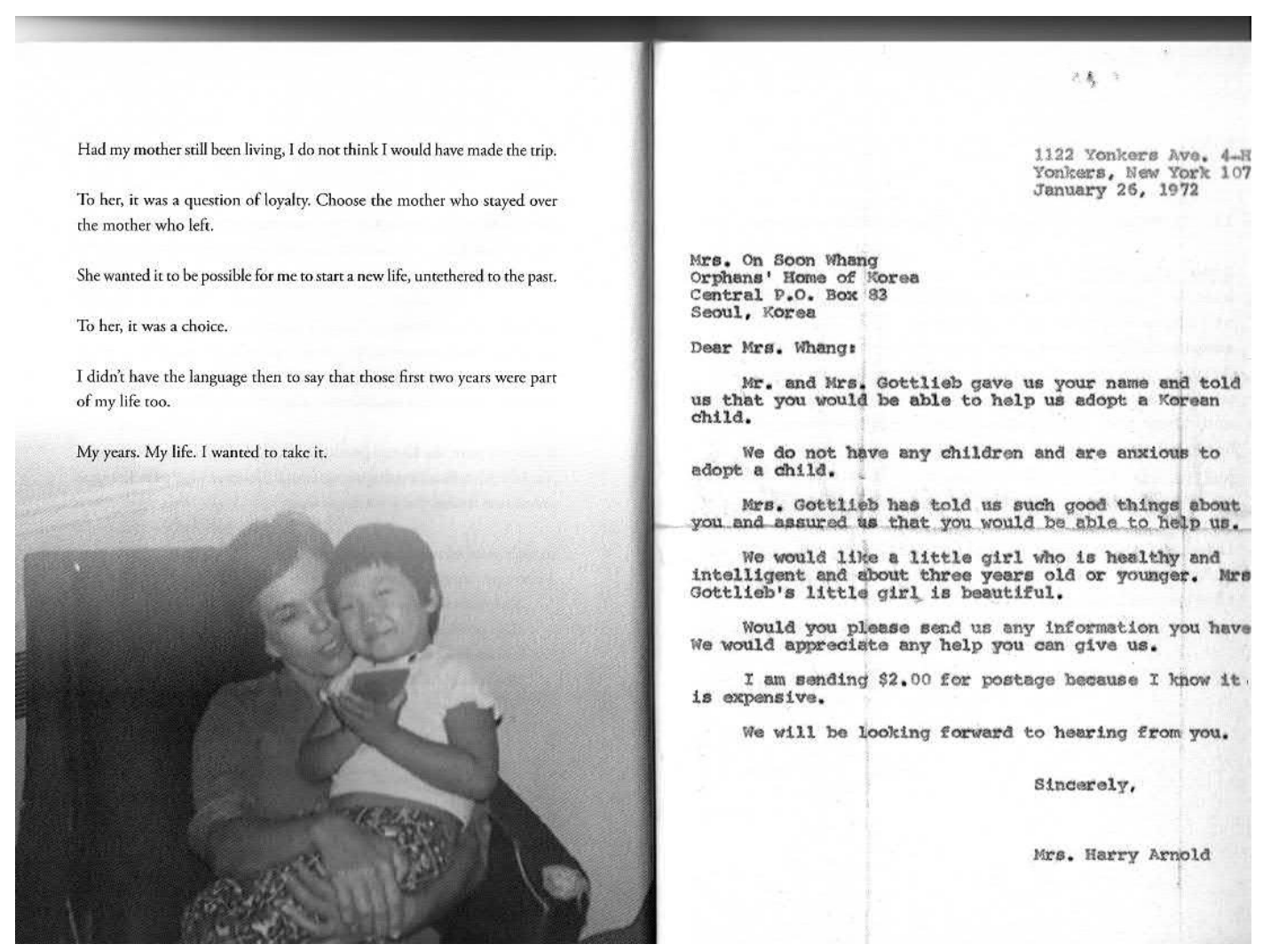

Figure 1: Smiling child sits on mother's lap (Arnold).

In her utilization of visual memorabilia, subversion of literary form, and inclusion of puns, Arnold construes herself as both an agent of meaning and a visual subject that is ultimately unknowable. In doing so, she unsettles the notion of a single and coherent self. As exemplified above, Arnold's memorabilia takes forms such as pictures, letters, segments of questionnaires, and other various correspondences. Throughout the text, these memorabilia are interspersed, written over, and transposed onto the page. At some places they are accompanied by Arnold's prose, and at others they stand alone. Although the very etymology of the word memorabilia suggests some inextricable linkage between objects and the memories they hold, Arnold's visual remains do not allow her to remember the past, satisfy deep-seated questions, or even necessarily spur meaningful recollection. Instead, they exist on a separate plane altogether, one that is realist, logical, and evidentiary, one in which experiences are neatly shuffled into the stable categories past and present. These objects are examples of what media theory philosopher Marshall McLuhan would call "hot media," or media that offers very little room for interpretation (McLuhan). They do not offer the room for imagination that other visual media do, such as cartoons or paintings. For Arnold, these neatly classified memorabilia are not so much nostalgic as much as they are simply documents of the past. Ultimately, while we may initially understand Arnold's memorabilia as 
snapshots of a reality that once existed, there remains a significatory gap between memory and reality.

In its exploration of the past as an inaccessible entity, Litany for the Long Moment raises questions about temporal continuity that cast the notion of a stable self into doubt. Throughout the text, Arnold juxtaposes past selves against present selves. At the center of her multimedia exploration is an important question: is the toddler who spoke Korean and lived in an orphan's house ultimately the same adult self who lives in the United States and speaks no Korean? The notion of a stable self relies on the compressing of selves over time; that is, the process of identity formation asks us to reconcile who we have been with who we are, and who we will be. Visual texts often disrupt this expectation of stability by introducing problems of memory and transfiguration. In reflecting on a photograph of himself that he could not remember having been taken, Barthes states, "this distortion between certainty and oblivion gave me a kind of vertigo, something of a 'detective' anguish" (Barthes 85). Here, there is a clear disjunction between forgetting and the irrefutable evidence of having-been that photographs provide. The experience of seeing a past self that one does not remember being is alienating precisely because the feeling wavers between certainty (with regards to the photographic testimonial) and ambiguity (with regards to the failure of memory).

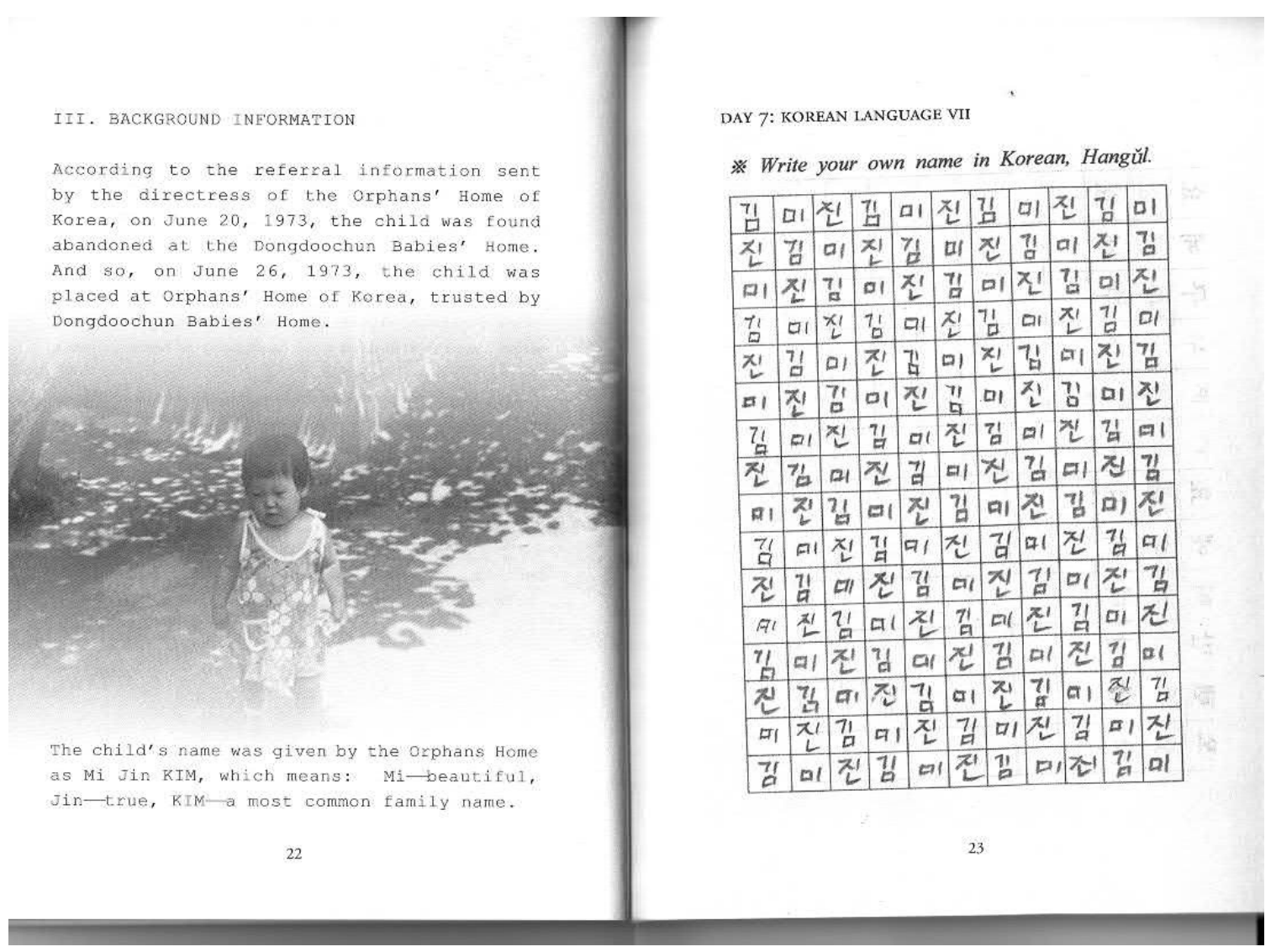

Figure 2: Picture of the author as a cbild in Korea; an image of the Korean alphabet (Arnold 22-23).

Meliora Vol. 1, Issue 1 
Moreover, there is a premonitory element to looking at photographs whose subject has since died or ceased to exist. The temporal gap such photographs pose upend the notion of a stable temporal reality. Barthes reflects on this issue when looking at a portrait of a man taken before his execution; the man is both "dead and going to die" and "dead and already dead" (Barthes 96). Here, a confusing collision of temporal states culminates in the certainty of loss.

On the left-hand side of the above image, the author references herself in the third person, stating, "the child was found at the Dongdoochung Babies' Home" (Arnold 22). Although Arnold is talking about herself in this passage, her use of the third person implies a distance between the viewer and subject of the memorabilia, invoking Barthes' concept of "detective anguish." The child is both Arnold and notArnold at once, just as the man in Barthes' text was "dead and going to die" and "dead and already dead" (Barthes 96). Furthermore, the author's use of passive voice in conjunction with the image-the child was "found" and "placed," the name "was given"-highlights the imposition of, rather than inhabitation of, identity. Arnold restates her own identificatory information in a distant tone, cleaving the signifier (the photograph) from signified (the self). This photograph opens a temporal rupture, and reflects Barthes' suggestion that photographs are evidence not of the past, but of "what-has-been," a temporal state that is at once past and present (Barthes 85). With this in mind, Arnold's prose objectively recapitulates the child's identificatory information, revealing that visual (or even material) documentation does not serve as evidence of any stable past. Rather, her impersonal reading dislocates the relationship between memory and memorabilia and insists on the inherent instability of visual documentation.

Just as Barthes discusses photographic subjects who have since died, Arnold reflects on a photograph of herself at the Orphan's Home in Korea. She states, "I know something about the future that this child does not: I know the life that she has had is about to end" (Arnold 27). While the life of the child in the photograph has already ended at the moment of Arnold's viewing it, the photographic subject remains innocent to this knowledge; the life of the child is therefore both about to end and long-ended. In reflecting on the work of Francesca Woodman, Arnold calls our attention to two key pieces of information: first that Woodman used herself as the subject for most of her photographs, and second that she died by suicide in 1981 . Then, Arnold states, "As viewers, we know something about the future that she does not" (Arnold 27). The "she" in this sentence functions syntactically to refer to Woodman-as-represented-in-photograph, and the present tense of 'know' recalls that represented self into being. The viewer's knowledge of Woodman's death as compared to the subject's (Woodman's) ignorance elides the past and present so that the loss itself is recapitulated at the moment of viewing. Throughout the text, Arnold writes into the rupture opened by this recapitulated loss. Moreover, Arnold's analysis of Woodman's work in this moment functions to put her own loss into conversation 
with Woodman's death. Here, death becomes a metaphor for the loss of a past self, or at least for its crushing unknowability.

For Arnold, it is precisely this unknowability that makes accessing the past (and past selves) all the more enticing. Susan Sontag states that photographs "turn the past into a consumable object" (Sontag 53). If desire is dependent on the (at least partial) inaccessibility of the desired object, then the past is something we desire to access, yet never fully can. Although Arnold contends with the fact that the past only manifests in barely-legible remnants throughout the text, she nonetheless desires to access it, to take or reclaim those first two years of her life. In one passage, she articulates the evasive nature of the past through a series of negations, stating, "I am continually drawn back, tethered to the wispy, blurred possibilities of the mother I will never know, a language I do not speak, the life I will never have" (Arnold 5). Here, Arnold's relationship to the past is defined by negation: "never," "not," "never." Arnold's syntactically negative invocation of the past suggest its ultimate unreachability. As previously referenced, Barthes explains that photographs do not reveal a seemingly stable past unspooling behind us, but rather, the "what-has-been" (Barthes 85). Within this formulation, the word 'has' implies the present perfect tense. We use this tense to talk about something that happened in the past but which is still true or continuing into the present. In the world of Arnold's text, Barthes' "what-has-been" suggests that the past is something we take with us rather than leave behind; yet, even so, it remains elusive to complete possession or consumption.

In a similar realm of negation, Francesca Woodman undergoes a feminist politics of refusal by acting as both the subject and object of her own images. Within the text, this dual positionality subverts gendered power dynamics ascribed to the field of photography and makes space for both Arnold and Woodman to craft their own feminized narratives. In order to fully consider Woodman's subversive tactics, it is first helpful to understand history's configuration of women as subjects to be looked at. Female objectification ultimately functions such that the body comes to garner meaning before (or even instead of) the person occupying that body. Its continual reification in visual forms ultimately hails the body as a signifier for selfhood. While Thy Phu's aforementioned concept of unmarked subjects is inextricably bound to the social construct that is race, we can also use it as a lens to analyze the role of gendered subjectivity in Arnold's text. In a gendered reading of "unmarked bodies," the female body is always already marked by and through the imposition of a gaze. Yet, by cleaving the nude female body from what it signifies, Woodman opens up a rupture in signification. In her inclusion of Woodman's photography throughout the text, Arnold writes into this rupture, and disrupts the relegation of women to strictly visual realms.

A consideration of feminist media theory elucidates the relationship between photography and the male gaze and underscores the subversive power of both Woodman's and Arnold's narrative-making. The photographic gaze feels inextricable 
from the male gaze, and, therefore, innately gendered. In relation to cinema, feminist media theorist Laura Mulvey explains that women are configured as silent images onto which meaning is imposed (Mulvey 7). In relation to photography, Susan Sontag discusses the intrusive force of the camera, which she states has a tendency to "presume, intrude, trespass, distort, [and] exploit" (Sontag 9). If women are historically positioned as spectacles to be looked at, then the (usually masculine) looker ultimately wields power over the looked-at. However, despite the intrusive masculine gaze of the camera, visual representation does not neatly map onto the real. In the text, Arnold quotes Jacques Lacan's claim that the "conceptualization of the 'real' woman is logically both unknowable and unspeakable." (Arnold 30). In grappling with unknowability as it relates to both Woodman's work and images of herself, Arnold undercuts visual modes of female objectification.

As a work of autobiography, Litany posits its author as both the subject and the object of her own gaze. Throughout the text, Arnold, undergoes a series of selfobjectifications, not only by including images of herself, but also by, at times, speaking about herself in the third person. Similarly, in Woodman's work, the photographer is both the shooter and the subject of the image. In the prologue of Litany, Arnold quotes critic Elizabeth Gumport's reflection on Woodman's long development process, writing, "In the end...[Woodman's] camera captures not the girl but the long moment it looked at her" (Arnold xiv). Although the subject of the photograph in question is, in fact, "the girl," it is "the long moment" that is captured. Despite the fact that her body is present in the image, Woodman herself evades capture. In citing Gumport here, Arnold articulates Woodman as both the maker (photographer) and repository (subject) of meaning. Both Woodman and Arnold embody both the subject and object of their own creative work, undermining the gendered power dynamics ascribed to the field of photography and opening space for each woman to forge forth in her own narrative-making.

Along with her subversion of gendered subjectivities, Arnold's utilization of unorthodox narrative structure underscores her narrative agency. ${ }^{2}$ Her writing is part prose, part poem. While at times Arnold's sentences are continuous and connect to form meaningful paragraphs, at other times they are broken up spatially so that readers are made to sit with the blank space between each distinct idea (see Figure 1), marking a departure from genre. In this essay, I choose to represent Arnold's blank spaces with line breaks so that the otherwise plain prose is elevated to poetry. In line with Arnold's departure from normative structure, the text is structured largely in response to an in-depth questionnaire. The questionnaire is part of an application for a Korean TV show meant to reunite adoptees with their biological families. The

\footnotetext{
${ }^{2}$ As I will discuss further, Arnold relinquishes categorical certainty in her narrative and submits to unknowing in much of her exploration of identity. Given this, the term 'agency' is not a totally sufficient term to describe the quality of Arnold's voice, but it is the closest to what I mean here-I would argue that she deploys 'agency' in a specific way that departs from that word's authoritative associations.
}

Meliora Vol. 1, Issue 1 
questions are vague, open-ended, and difficult to answer: for example, the first of these is "WHO ARE YOU LOOKING FOR?" (Arnold 3). The capitalization of this question and all subsequent questions functions to highlight their insurmountability. Arnold does not answer the questions with any explicit certainty; rather, she uses them as a literary tool to divide her narrative into a number of sections. Moreover, some questions are repeated throughout the text, and Arnold subverts the format of the questionnaire by giving differential "responses" each time. The way Arnold's prose works around these questions rather than in direct response to them has the effect of allowing the reader to simmer in the instability of the question-and-answer format as a means through which to distill subjectivity. In fact, Arnold's refusal to provide answers about herself calls into question the definition of subjectivity itself. Is subjectivity defined by having a stable identity throughout time? In the world of Arnold's text, an assemblage of materials that construe subjectivity at the same time as they obscure details about the subject, the answer is a tenuous 'no.'

Building off of her unorthodox narrative structure, Arnold engages in a series of puns that cleave words from their traditional meanings and upend readers' expectations around what language is meant to signify. When reflecting in the prologue on Francesca Woodman's life, Arnold considers the phrase “to take [one's] own life." She states, "I want it to mean something other than it does. / Want it to mean not ending a life, but claiming it. Taking it in" (Arnold xiv). Arnold subverts a phrase that connotes a definitive ending. Instead, she articulates it in terms of its potential for "claiming," or ownership. In relation to the role of women as photographic subjects, this claiming that Arnold calls for connotes a taking-hold of one's own narrative subjectivity. Here, it is not the viewer that defines the subject in the photo, but the subject herself who sets the terms and definitions. This dual positionality shifts the narrative perspective from the viewer of a life to the subject of that life, casting the (feminized) self as both gazer and gazed-at.

Arnold also considers the Korean questionnaire in relation to puns, making use of its mistranslations to reveal the proliferative potential of words and their meanings. The TV show that asks its participants to fill out the questionnaire is called "I Miss That Person." Arnold states, "I find the awkwardness of the title rather charming, but it makes me think of missing as in targets. Like: / I am aiming at you but I keep missing" (Arnold 7). Arnold's violent rendering of this sentimental term drastically recasts our definition of the initial word, and posits Arnold as the maker of meaning. Her pun on 'missing' highlights the violence of an inaccessible past. The image of a gun and a target also conjures Barthes' conception of the "punctum," that barely distinguishable element of every photograph that draws the viewer to it. Barthes defines a punctum as a "sting, speck, cut, little hole-and also a cast of the dice. A photograph's punctum is that accident which pricks me (but also bruises me, is poignant to me)" (Barthes 27). For Barthes, a photograph is compelling because of the jolt of pain it engenders in the viewer; for Arnold, the 
sentimentality of missing is rife for analysis because of its violent potentiality. Moreover, the concept of 'missing' is also meaningful because it evokes desire in photography, something we are drawn to but cannot grasp. Ultimately, Arnold's utilization of puns subverts readers' expectations of language and underscores her departure from normative forms, which underscores, in turn, her destabilized notion of a stable and accessible self.

By using visual elements to rupture the continuity between past and present, working around rather than in direct response to the questions she poses, and cleaving words from their normative meanings, Arnold construes herself as both an agent of meaning and a visual subject that is ultimately unknowable. In doing so, she destabilizes the notion of a single and coherent self. Her engagements with photographs and photography theory reveal the wide gaps between visual representation and memory. These gaps underscore the unreliability of photographs to represent the past. Moreover, Arnold's investment in Woodman as an evasive female subject reveals her disillusionment with stable modes of visual representation. Arnold's investment in unknowability extends beyond her problematization of memory to encompass the divide between racialized bodies and interior experience. Not only does she unsettle the notion of a stable self in relation to photography and visual representation, she also does so in relation to identificatory categories and the problem of the body as a signifier of race. In doing so, she departs from dominant inclusion rhetorics that presuppose certain molds of racial embodiment and being.

\section{Bodily Disjunction and Racial Signification}

"In emphasizing the intersections between a body of work whose subject is in fact the body, with a body of theory that renders the body problematic, I intend no hard and fast correspondences, no fixed equivalence."-Abigail Solomon-Godeau, "Just Like a Woman"

"The body still remains the sticking point by which social distinctions and differences are generated and defined."-Josephine Lee, Asian North American Identities

Similar to photography's failure to represent visual subjects, racial categories of identity fail to capture the individuals they attempt to represent. For Arnold, racial categories pose a familiar problem of signification: what are bodies beyond what they are seen to mean? If visual media does not fully account for its subjects, racial categories do not account for the nuances of individual identity. Such categories falsely claim to empower marginalized individuals through induction into dominant frameworks of identity and visibility. Those with non-dominant experiences even

within the category of Asian American are made doubly invisible through their lack 
of adherence to racial frameworks. However, throughout the text, Arnold disrupts racial frameworks by recounting moments in which she was inaccurately racialized by a white gaze. An analysis of these moments through the lens of critical race theory reveals the instability of racial categories, and the ways in which they fail to represent selfhood. By not providing alternatives to dominant frameworks of identity categorization, Arnold submits to a framework of unknowing in line with what I read as her larger project of critiquing visual media for its failure to represent individuals.

For Arnold, the figure of the adoptee is always already out of place, a marked body with an unmarked history-what Thy Phu would call an "unmarked subject" (Phu 18). This is especially true for Arnold, a Korean adoptee transplanted into a white family. Throughout the text, Arnold contends with memories wherein instances of racism make clear the divide between visual appearance and subjectivity. Even outside of the unique positionality of the adoptee, the terminology we have at our disposal to describe identities within the Asian American diaspora is never specific enough to encompass the experience of having a particularly racialized body. In the context of the United States especially, white is seen not as a race, but as a default. Anything that falls outside of it is prone to the imposition of various complex terms in attempts to understand the 'other.' As Sean Metzger articulates, "the endless multiplication of ethnic identity categories through such a structure tends to occur without a critique of the flows of power that produce and maintain minority status" (Metzger 63). Similar to how visual media fails to represent its subjects, categories of identity are not sufficient to fully represent the individuals they attempt to group.

Identity is always already inflected by history. When thinking about the positionality of Asian Americans in the U.S., it is critical to consider the slew of antiimmigration laws that have figured Asian Americans as unassimilable aliens, unable to escape the label of 'other.' White supremacist ideologies are placated by the categorization of these others, and it is through this categorization that whiteness maintains its power. Hegemonic construction of race often puts forth a generalized set of categories into which an Asian body must fall in order to be understood by the white (or otherwise dominant) gaze. For example, the term "Asian" is associated with physical characteristics such as light skin, dark hair, slant eyes, and a thin body. These traits presuppose an East Asian background and marginalize ethnicities or individuals whose bodies depart from this set of characteristics.

Within these already violent categorical expectations constructed around the Asian American racialized figure, individuals who lack fixed equivalence to whatever culture their visible race presumably corresponds to are subject to further scrutiny and interrogation. Adoption, cultural alienation, assimilation pressure, Americanization, and familial loss are a few examples of hegemonic forces that further marginalize individuals within the Asian American diaspora. In the face of a white gaze that assumes direct correspondence between visual signifiers and race, 
ethnicity and nationality, and seeing and being seen, such subjects are grouped in with other dominant ethnic categories and thereby rendered invisible.

In relation to white perceptions of the Black body, Frantz Fanon states, "And there you have it; I did not create meaning for myself; the meaning was already there, waiting" (Fanon 113). In Fanon's formulation, Black people are subject to the meaning-making of others; that is, the dominant (white) gaze assigns meaning to them before they can assign meaning to themselves. As Fanon sifts through these racial dynamics, he suggests that racial or identificatory meaning becomes meaningless through a homogenizing white gaze. The fraught divide between interior experience and exterior being is rooted in the notion that ambiguous or 'foreign' bodies must conform to a racial rubric in order be meaningful, or, in other words, understandable. The racial body therefore becomes a spectacle for scrutiny, itself a visual stand in for race. In considering the gap between the body and what it signifies, a question arises: what are bodies beyond what they are seen to mean? As Arnold delves into the particularities of her lived experience as a Korean adoptee raised by white parents, she explores the meanings assigned to and reclaimed by racially bodied individuals.

From a photographic lens, possible selves in Arnold's text manifest in the divide between past and present, in the self that was versus the self that is; they also manifest in the divide between interior experience and exterior perception. As Josephine Lee articulates in the epigraph to this section, the body is the "sticking point by which social distinctions and differences are generated and defined" (Lee 103). Despite Arnold's lack of connection to Korean culture, Arnold's body is nonetheless inculcated into pre-existing racial rubrics that determine identificatory meaning for her before she might do so herself. ${ }^{3}$ Subjectivity is cast into uncertainty, held in suspension between imposed and self-made meaning.

In relation to this uncertainty, Arnold articulates a moment in childhood wherein a group of boys yelled racial epithets at her:

They spotted me as they unloaded their car, pointing fingers and calling out, 'Attack! It's Pearl Harbor!' / They ran circles on the sidewalk, making shooting sounds with their mouths. / I did not know anything about Pearl Harbor then, and I suspect that what they knew was limited too. / Later, when I learned about the Japanese, I wanted to go back and tell them: 'Korean. Not Japanese. There is a difference.' / But back then, it did not matter. (Arnold 79)

${ }^{3}$ Assuming we are defining culture in a normative sense, meaning immersion in language, country, and cuisine. That is, my highlighting of Arnold's lack of connection to Korean culture is not to say that ethnic connection cannot be forged through other means than these, but to make clear the impossibility of the body as representative of 'culture.'

Meliora Vol. 1, Issue 1 
This passage suggests a problem of identity that ultimately traces back to those regulatory racial rubrics used to impose meaning onto racialized bodies. The boys' pointing of fingers and calling out defines Arnold as a specific kind of subject. This subject-making conjures French philosopher Louis Althusser's work on interpellation, or that moment wherein a subject becomes a subject; that is, that moment wherein an individual becomes inculcated into the repressive or ideological state apparatuses through which hegemony functions (Althusser). While understanding interpellation can be nebulous work, the key to Althusser's definition of the term is the notion that becoming a subject is very much a process-it does not occur instantaneously, and relies on various pressures of socialization. For racially-bodied individuals, to become a subject is to become visually meaningful to a white gaze. Racial subjects become visually meaningful (and, therefore, recognizable) through an induction into racial ideology, which is in large part mediated by racial rubrics. For nonwhite individuals, then, becoming a subject means undergoing an induction into the very ideology that defines them as 'other.' Though Arnold does not subscribe to a racial ideology of identity formation, she nonetheless remains bound to it.

Although the boys' epithets seem to impose race onto Arnold, these comments do not configure Asian-ness in terms of its nuanced historical grooves. Rather, they serve to position her within a pre-ordained set of categories in which she is defined by her otherness. As quoted by Sean Metzger, Kandice Chuh writes that "a 'subject' only becomes recognizable and can act as such by conforming to certain regulatory matrices" (Metzger 277-78). In the passage from the text that I have quoted above, the pointing boys assign Arnold's body a category within this matrix: Japanese-ness. Although Arnold's reflection on this moment in the text is embedded with her desire to correct this case of mistaken identity, in the moment, "it did not matter." The boys call out to Arnold with the words "Attack" and "Pearl Harbor," obviously referencing the 1941 military strike. Yet, as Arnold writes, "I did not know anything about Pearl Harbor then, and I suspect that what they knew was limited too." While these terms conjure images of violence and bring up a racist history, I would argue that the boys are not attempting to recall that specific history in any meaningful way. Instead, this instance of interpellation is meant to associate Arnold's body with a pre-ordained ethnic category, to align her with what the viewer thinks she must represent. It is through the boys' seamless enjoining of signifier and signified that they impose a racial category onto Arnold's body, which here functions merely as a visual representative for race. In other words, Arnold becomes a meaningful subject in the eyes of these boys through their act of racial interpellation.

This is not the only instance in the text in which Arnold reflects on a moment of racial interpellation. On the playground, she states, "I was only ever Chinese or Japanese." She goes on to chronicle a conversation between a presumed classmate: “'Korea, the country. It's where I was born. Korean.' / 'No. You're either 
Chinese or Japanese. Which?”' (Arnold 80). In this case, Arnold's unmarked body falls into the gap between "Chinese" and "Japanese," the two racial categories into which her body is allowed entrance. As Chuh states, "Asiannness has been racialized as immutably foreign despite nativity, citizenship, or acculturation within the US frame" (Chuh 618). Therefore, Arnold's body becomes recognizable to the white gaze only through a limited set of racial categories-in this case, Chinese or Japanese. In these scenes of bodily disjunction, the children's attempt to impose meaning onto Arnold is only possible through adherence to fixed categories of race, in this case their absolute insistence on the binary "Chinese or Japanese." Nevertheless, throughout the text, Arnold highlights moments in which her unmarked body remains un-representable through identifiable categories. Her focus on bodily disjunction instantiates a destabilizing of racial categories themselves.

Arnold's disillusionment with fixed equivalence between the racial body and its cultural and historical 'meaning' conjures Lisa Lowe's work on heterogeneity within the category of Asian American identity. In discussing a variety of Asian American works of literature, Lowe states:

Asian American discussions of ethnicity are far from uniform or consistent; rather, these discussions contain a wide spectrum of articulations that includes, at one end, the desire for an identity represented by a fixed profile of ethnic traits, and, at the other, challenges to the very notions of identity and singularity which celebrate ethnicity as a fluctuating composition of differences, intersections, and incommensurabilities. (Lowe 534)

Some Asian Americans who participate in discussions of ethnicity find solidarity via identifying shared experiences, such as certain filial relations or generational conflicts. On the other hand, the very nature of these discussions illuminates the innumerable differences within the Asian American community, such that the only common link that can be made between individuals in the diaspora is that of difference itself. Litany for the Long Moment posits the body as the site of this difference and explores racial-cultural disjunction as an interaction occurring within and between bodies. For Arnold, Asian American intra-cultural differences are most succinctly articulated through engagements with the self as a visual signifier, whether that signification manifests in photography or the body itself. In order to combat meta-narratives that elide central differences between Asian Americans, Lowe posits a theory of heterogeneity, which she argues "provides a position for Asian Americans that is both ethnically specific, yet simultaneously uneven and unclosed" (Lowe 538). Arnold's unorthodox articulation of identity throughout Litany evokes a similar unevenness, which provides space for the proliferation and recognition of diasporic difference. In Lowe's words, it is through this recognition of intracultural difference that Asian American equivalency becomes "redefined by a lack of closure" (Lowe $538)$.

Meliora Vol. 1, Issue 1 
I am interested in thinking about this "lack of closure" in relation to Arnold's investment in lack as a vessel through which to interrogate selfhood. The original epigraph that spurred the onset of this project- "writing into the rupture"-itself posits lack as a precondition for creation. Arnold's lack of knowledge about her past spurs her to write "into" that past; into the inaccessibility of memory, the alienating lack of equivalence between past and present self, and the disjunction that comes with existing in a racial body. As I have begun to make clear throughout this project, it is Arnold's awareness and embracing of not-knowing that makes her voice distinct and defines her narrative agency. Moreover, Arnold's toppling of racial categories throughout the text functions to dismantle knowledge systems around identity construction. Arnold does not necessarily provide readers with any alternatives to these orthodox knowledge systems-those that contour not only race, but also gender, genre, narrative structure, and referentiality. When Arnold refuses to provide an alternative, she calls into question the sufficiency of knowledge as a tool for distilling identity.

In her call against eliding differences within the category of Asian American, Kandice Chuh takes on questions of knowledge from a poststructuralist angle, defining poststructuralism through its "radical destabilization of fixity and transparency in language" (Chuh 4). While my project does not approach questions of knowledge from a language-centered viewpoint, Chuh's work provides a useful lens. Her notion of the knowing subject is relevant to the themes of instability and un-knowing that inhere in Arnold's text. ${ }^{4}$ Chuh states that "poststructural thinking corrodes the authority of the 'knowing' subject, whose grounds for action are consequently called into question. Here, subjectivity is conceived as an unstable construct of repressive/constructive orders of knowledge" (Chuh 5). Arnold is no such 'knowing' subject, and she does not wield authority over her story in any traditional sense. Even so, her voice remains lucent and distinct. Arnold's specific and authoritative voice suggests that some kind of agency is possible even when that agency is defined by a lack of, rather than claim to, knowledge about oneself. Readers are compelled by Arnold narrative and are inclined to follow her through this nuanced parsing of identity that ultimately does not end in any definable or certain answers. Paradoxically, the only definable construct that this narrative expresses and answers to is unknowability itself.

\section{Conclusion}

\footnotetext{
${ }^{4}$ While not the center of my project in this thesis, it is worth noting that the topic of language is rife terrain for discussions of identity throughout Arnold's text, particularly in terms of the role of the 'mother tongue' and the author's difficulties with making the unfamiliar oral contortions that Korean necessitates while attempting to learn the language as an adult.
} 
Litany for the Long Moment is a lucid exploration of selfhood that navigates the role of the photographic image and the disjunction between photographs and memories. Looking at images from the past can cause temporal ruptures that unsettle the notion of a stable self, calling into question the meaning of subjectivity. Arnold's use of memorabilia throughout the text reveals that past objects, whether photographs, documents, letters, or other miscellaneous things, do not spark newfound access to the past. Rather, these memorabilia open up further space in which to contend with the gaps between both memory and evidential image and past and present self. Arnold's integration of the work of Roland Barthes and Francesca Woodman bolsters this configuration of memory and memorabilia as it relates to identity as an ever-shifting entity. Moreover, her engagement with the slippery signification of words figures the self as endlessly proliferative, regenerative, and multitudinous.

Furthermore, Arnold's exploration of her Korean identity highlights the problem of the racial body and what it signifies. Within the hegemonic constructs of knowledge that shape identity, the racial body comes to act as a visual representative of otherness. Throughout the text, Arnold chronicles a number of moments involving bodily disjunction which reveal the invisibilizing gap between looker and looked-at. For Arnold, and in conjunction with feminist media theory and critical race theory, this gap is both gendered and racialized. Arnold's exploration of bodily disjunction disrupts the concept that racial bodies meaningfully signify anything. Rather, visuality in Litany for the Long Moment is contoured by lack-lack of history, memory, culture, and, ultimately, personal signification around what it means to exist in a racial body. In delving into the un-representability of the racial body, Arnold reveals that visual representation cannot authenticate or validate being, and that visual representation itself is an insufficient mode of racial empowerment.

One moment that crystallizes Arnold's project throughout Litany for the Long Moment occurs after she puts two seemingly disparate concepts into conversation. In one sentence, she reflects on Francesca Woodman's suicide, and how this artist's photographs live on and continue to reveal "the constant tension between seeing and being seen" (Arnold 29). In the next, she discusses the conspicuous experience of growing up Korean in a white family, in a white neighborhood. At the bottom of this page, deftly linking these two realms, Arnold states, "But being visible is not the same as being seen" (Arnold 29). This section epitomizes the mosaic nature of Arnold's writing, and her seamless shifting from one topic to the next is helped by the text's deeply referential quality. In the final sentence, the word "But" stops us in our tracks and causes a nick that then opens up space for problematization. Here, "But" functions as a rupture, and not one that offers an alternative to the critique it implies. Rather, "But" swoops in and shifts the definition of subjectivity from "visibility" to "being seen." In enacting this shift, Arnold engages with the subtle distinctions laid out in her entire project. These distinctions are ones that refute 
dominant frameworks of visuality and racial categories as rubrics through which to determine the self. Instead, they embrace nuance, unknowability, and lack as entry points into navigating identity. Litany for the Long Moment is, at its core, Arnold's radical attempt to 'see' herself_-not simply through images, but through a critique of dominant frameworks and a refusal to provide alternative structures through which to discern identity.

Arnold's key distinction between "being visible" and "being seen" is what sparked my interest in this project. I have long felt disillusioned with dominant modes of Asian American empowerment that rely on visibility, on the widespread viewing of racial bodies in various forms of media and corporate enterprises. Inclusion rhetoric tells us that the more certain minority identities are present within certain social or professional spheres, the further we have come. But what is 'far?' What is 'come?' This model relies on a false equivalency between racial integration and racial empowerment. The very notion of inclusion is tenuous in that it presupposes a center towards which all subjects must strive to adhere, and the centrality implicit in inclusion rhetoric does not speak to the myriad differences, identities, and particularities within minority communities. Within this false formulation of racial empowerment, there will always be someone whose history or experience remains unseen, at least partially. If inclusion is predicated on invisibilizing certain subjects, Arnold's project departs from this configuration altogether, instead finding its power in the ruptures that occur when we contend with the fact of our difference and unknowability. Ultimately, Arnold reveals that our lack of access to ourselves and to our pasts is in fact fertile terrain for interrogating what it means to be a self. When we submit to unknowing, we find a new kind of power, one divorced from the hegemonic structures that otherwise define the concept of identity. Here, a rupture is an opening, and one that should be explored to its fullest extent.

\section{WORKS CITED}

Althusser, Louis. "Ideology and Ideological State Apparatuses." Translated by Ben Brewster. La Pensée, 1970.

Arnold, Mary-Kim. Litany for the Long Moment. Essay Press, 2018.

Barthes, Roland. Camera Lucida: Reflections on Photography. Translated by Richard Howard. Reprint edition. Hill and Wang, 2010.

Chuh, Kandice. Imagine Otherwise. Duke University Press, 2003.

"Of Hemispheres and Other Spheres: Navigating Karen Tei Yamashita's Literary World." American Literary History 18, no. 3 (Fall 2006).

Fanon, Frantz. Black Skin, White Masks. Revised. New York: Grove Press, 2008. 
Lee, Josephine. "Asian America Is in the Heartland: Performing Korean Adoptee Experience." In Asian North American Identities: Beyond the Hyphen, edited by Eleanor Ty and Donald Goellnicht. Indiana University Press, 2004.

Lowe, Lisa. "Heterogeneity, Hybridity, Multiplicity: Marking Asian American Differences.” In Contemporary Asian America: A Multidisciplinary Reader, by Min Zhou and Anthony C. Ocampo, 3rd ed. NYU Press, 2016.

McLuhan, Marshall. Understanding Media: The Extensions of Man. The MIT Press. The MIT Press; Reprint edition, 1994.

Metzger, Sean. "At the Vanishing Point: Theater and Asian/American Critique." American Quarterly 63, no. 2 (June 2011): 277-300.

Mulvey, Laura, and Sue Thornham. "Visual Pleasure and Narrative Cinema." In Feminist Film Theory: A Reader. Edinburgh University Press, 1999.

Phu, Thy. "Decapitated Forms: Theresa Hak Kyung Cha's Visual Text and the Politics of Visibility." Mosaic: An Interdisciplinary Critical Journal 38, no. 1 (March 2005): 17-36.

Sontag, Susan. On Photography. Farrar, Straus \& Giroux, 1973.

HANA RIVERS, Barnard College '20, majored in English, concentrated in Creative Writing, and minored in Women's, Gender, and Sexuality Studies. She currently works as the Post Baccalaureate Fellow at Barnard's Center for Engaged Pedagogy to advocate for anti-oppressive teaching and learning. Her fields of interest include critical race studies, Asian American literature, and creative writing. 